This item is the archived peer-reviewed author-version of:

\title{
Institutional predictors of the adoption of employee social media policies
}

\section{Reference:}

El Ouirdi Asma, El Ouirdi Mariam, Segers Jesse, Pais Ivana.- Institutional predictors of the adoption of employee social media policies

Bulletin of science, technology and society - ISSN 0270-4676 - (2015), p. 1-11

Full text (Publishers DOI): http://dx.doi.org/doi:10.1177/0270467615623885 
Institutional Predictors of the Adoption of Employee Social Media Policies

Asma El Ouirdi ${ }^{\text {a }}$,, Mariam El Ouirdi ${ }^{\text {a }}$, Jesse Segers ${ }^{\text {a, b }}$, Ivana Pais ${ }^{c}$

${ }^{a}$ Faculty of Applied Economics, University of Antwerp, Stadscampus Prinsstraat 13, S.B.216, 2000, Antwerpen, Belgium. (+3232655025)

${ }^{\mathrm{b}}$ Antwerp Management School, Sint-Jacobsmarkt 9-13 / BE-2000 Antwerpen, Belgium. $(+3232654758)$

${ }^{c}$ Università Cattolica del Sacro Cuore, largo Gemelli 1, 20123 Milano, Italy. (+393403367939)

Asma.ElOuirdi@student.uantwerpen.be

Mariam.ElOuirdi@student.uantwerpen.be

Jesse.Segers@ams.ac.be

Ivana.pais@unicatt.it

* Corresponding author 
Institutional Predictors of the Adoption of Employee Social Media Policies

\begin{abstract}
The importance of employee social media policies is recognized in today's increasingly connected organizations. Yet these policies are adopted at varying rates in different sectors and geographical regions. In the present study, an institutional approach was employed to investigate the predictors of the adoption of employee social media policies by organizations. Six predictors were examined, namely organizational size, industry, and the national culture dimensions of power distance, individualism, masculinity, and uncertainty avoidance. Results of a logistic regression analysis of 558 online survey responses from human resource professionals worldwide showed that all six predictors were associated with the adoption of employee social media policies. These findings have implications for multinational companies, as well as for policy makers in the legal, human resources, information technologies, and public relations departments who are the primary parties involved in establishing employee social media policies. Study limitations are presented and future research avenues are suggested.

Keywords: Employee social media policies; employee social media guidelines; social media governance; institutional theory; national culture; cultural dimensions theory.
\end{abstract}


Institutional Predictors of the Adoption of Employee Social Media Policies

\section{Introduction: Employee Social Media Policies}

Social media have become an integral part of the 21st century's workplace. These new media are highly interactive platforms that use mobile and web-based technologies (Kietzmann, Hermkens, McCarthy, \& Silvestre, 2011), and offer the possibility of reaching and involving large audiences (M. El Ouirdi, El Ouirdi, Segers, \& Henderickx, 2014). Social media use in the workplace is complex and multifaceted because it can be intended for organizational or individual uses, targeted at internal or external crowds, or designed for professional or personal purposes (A. El Ouirdi, El Ouirdi, Segers, \& Henderickx, 2014).

Several researchers and practitioners have examined the benefits and risks of social media use by employees. On the one hand, employees can be more creative when they use social media to create knowledge and seek information beyond organizational boundaries (Yan, Davison, \& Mo, 2013). They become more satisfied with their jobs when they use these technologies in the workplace (Charoensukmongkol, 2014), and they can act as brand ambassadors on social media to convey corporate culture and attract new talent (Laick \& Dean, 2011). Social media can also foster collaboration and trust among the members of an organization (Murthy, Hastings, \& Mawrie, 2014). On the other hand, however, social media use by employees can give rise to privacy and reputation issues (Cain, 2011; Protiviti, 2013, 2014), and lead to legal ramifications and workplace disputes (Hidy \& Mcdonald, 2013) as well as stress and information overload (Bucher, Fieseler, \& Suphan, 2013). Therefore, organizational initiatives are needed to prevent potential issues related to social media use in the workplace while fully benefiting from these technologies. 
This study is aimed at investigating the predictors of the adoption of employee social media policies, focusing on the role of organizational size, industry sector, and national culture dimensions. The cultural perspective, in particular, is useful for policy makers in multinational companies who need to adapt employee social media policies to different cultural contexts. This is all the more true in today's globalized business world where there is a strategic need to understand how national culture influences behavior in organizational settings (Sagie \& Aycan, 2003). The findings of this study will help provide guidance to policy makers in the legal, human resources, information technologies, and public relations departments who are the primary parties involved in establishing employee social media policies (Neill \& Moody, 2015; Tufts, Jacobson, \& Stevens, 2015). This study will also contribute to the underresearched topic of employee social media policies (A. El Ouirdi et al., 2014; Fast, Sørensen, Brand, \& Suggs, 2015) by providing preliminary empirical results on how institutional factors affect the adoption of these policies.

This article is structured as follows: First, employee social media policies are defined and their importance is highlighted, followed by a brief literature review on the small corpus of research on the topic. Second, based on an institutional approach, hypotheses are advanced on the role of organizational size, industry sector, and the four national culture dimensions of power distance, individualism, masculinity, and uncertainty avoidance in predicting the adoption of employee social media policies. Third, the study methods, results, and limitations are presented, and future research avenues are suggested.

\section{Research Background and Literature Review}


Organizational measures regarding social media use by employees can take the form of either social media policies or guidelines. The difference between these two types of documents is that policies provide official positions governing social media use by employees, while guidelines provide advice on best practices (Hrdinová, Helbig, \& Peters, 2010). Furthermore, these policies or guidelines can be either separate documents, or integrated within existing information technology policies (Jacobson \& Tufts, 2013). Throughout this article, "employee social media policies" will be used as an umbrella term. This choice is based on the general definition of an organizational policy as "a communication document from management, as management attempts to convey a specific message to various parties" (Von Solms \& Von Solms, 2004, p. 275), without necessarily entailing official positions or any mentions of conduct consequences.

Employee social media policies are different from other workplace directives, although they can be thought of as an extension of existing Internet and e-mail policies. Most organizations build employee social media policies on established and well-understood corporate communication policies in an attempt to integrate the new phenomenon of social media into existing knowledge (Kaganer \& Vaast, 2010). Research has shown, however, that traditional organizational policy development processes are unsuitable for social media-related issues (Husin \& Hanisch, 2011a, 2011b). The development of employee social media policies requires increased feedback from different management layers in order to face new social media issues that are not anticipated with more traditional tools such as e-mail (Husin \& Hanisch, 2011a).

Employee social media policies are generally adopted in the framework of a larger organizational approach or strategy. These policies are considered as one of the main vehicles of social media governance (Linke \& Zerfass, 2013; Vaast \& Kaganer, 2013) defined as "the formal 
or informal frameworks which regulate the actions of the members of an organization within the social web" (Zerfass, Fink, \& Linke, 2011, p. 1033). Employee social media policies represent only one step in an organization's strategic management approach to the use of social media by employees (Dreher, 2014) and one of the strategic responsibilities associated with social media management in general (Neill \& Moody, 2015). The broader framework that employee social media policies are part of may include employee training, a supporting corporate culture, and managerial commitment, among other aspects (Dreher, 2014; Linke \& Zerfass, 2013). Additionally, the existence of social media policies may be considered as an indicator of organizational readiness toward a successful social media implementation (Geyer \& Krumay, 2015).

In organizational contexts, employee social media policies are important for two main reasons. First, from an employees' perspective, these policies can help preserve job security by educating employees about safe online conduct as well as critical online behaviors that might get them fired because information posted on online social networks can be used as the basis of disciplinary actions or even termination decisions by human resources managers (Davison, Maraist, \& Bing, 2011; O’Brien, 2014). Employee social media policies are particularly important in countries where the legal frameworks protecting employee social media behaviors are not sufficiently developed yet.

Second, from an organizational perspective, employee social media policies can help organizations attract potential job candidates. For young job applicants, the existence of an employee social media policy is important. For example, according to a survey conducted by Cisco (2011), 24\% of college students in a large cross-cultural sample stated that they would ask about an organization's social media policy during a job interview. Furthermore, many young 
students reported that they would decide about job offers based on the content of the social media policies of potential employers (Cisco, 2011). Results from the same study showed that if offered a job from an organization that banned social media access during work hours and on corporate devices, $27 \%$ of the surveyed students would accept it but still access those platforms. In contrast, 29\% would not accept the offer because they consider the hiring company in question to be behind the times in terms of social media use, and they believe that access to social media is part of the younger generation's culture and a prerequisite for their work-life balance (Cisco, 2011). Other empirical evidence supported these results by showing that the Millennial generation perceived a better person-organization fit with companies whose policies supported employees' use of social media than a fit with organizations that restricted such practices (Cho, Park, \& Ordonez, 2013).

The investigation of the policy-related aspect of social media use by employees is therefore a timely endeavor, given the shifts that are currently marking the composition of the workforce worldwide (Barzilai-Nahon \& Mason, 2010; Murphy, 2007). Workforce demographics are changing as younger workers are increasingly joining organizations, which gives rise to technology-related issues such as network overload and inefficient multitasking due to using new information and communication technologies at work (Barzilai-Nahon \& Mason, 2010).

While the importance of employee social media policies is clearly established, practitioner reports show that organizations are still divided on their adoption. Between 2009 and 2015, the rate of organizational adoption of these policies varied between $20 \%$ and $63 \%$ in different sectors and geographical regions (Deloitte, 2009; ERC, 2012; Fry, 2013; Macnamara, 2011; Manpower, 2010; Neill \& Moody, 2015; Proskauer, 2011; Protiviti, 2013, 2014; Tufts et al., 2015). 
Furthermore, the corpus of research on social media policies is limited and focused on a few topics. One of the aspects examined in the literature on social media policies is their legal framework, especially in the United States. Several researchers discussed employee social media policies in relation to American laws such as the National Labor Relations Act, and presented several illustrations of court cases involving employees' use of social media (e.g., Berkowitz, Downes, \& Burdick, 2012; Brice, Fifer, \& Naron, 2012; Cavico, Mujtaba, Muffler, \& Samuel, 2013; Elefant, 2011; Hudson \& Roberts, 2011; Kennedy, 2013; Kirby \& Raphan, 2014; National Labor Relations Board, 2012; Neal, 2012; O’Brien, 2014; Thornthwaite, 2013; Younkins, 2013). Nevertheless, while social media are evolving quickly, legal frameworks are progressing at a slower pace, leaving employers struggling with the adoption of proper policies that allow them to benefit from social media all the while avoiding legal and ethical issues (Kaupins \& Park, 2011). Several researchers have focused their efforts on analyzing the content of social media policies with the objective of identifying recurrent themes and guiding policy development (e.g. Fast et al., 2015; Hrdinová et al., 2010; Jacobson \& Tufts, 2013; Johnston, 2015; Krüger, Brockmann, \& Stieglitz, 2013).

Another aspect noted in the literature on social media policies is its focus on the health care sector, with attention divided between physicians (Decamp, 2013; Greysen, Kind, \& Chretien, 2010) and medical students (Chretien, Greysen, Chretien, \& Kind, 2009; Kind, Genrich, Sodhi, \& Chretien, 2010). This interest can be explained by the sensitivity of the current and future jobs of these users, especially with regards to patient privacy and confidentiality that might be at risk of violation on social media, especially with the increasing adoption of social technologies in the medical profession, also called "Medicine 2.0" (Eysenbach, 2008). This interest is further accentuated by the contribution of the American Medical Association to the topic by issuing a 
policy entitled "Professionalism in the Use of Social Media", designed to provide advice for physicians and medical students on how to use social media (Oakley \& Spallek, 2012).

\section{Predictors of the Adoption of Employee Social Media Policies}

In this study, the adoption of employee social media policies is examined in relation to the organizational boundary of company size and extended beyond it to the institutional factors of industry and national culture dimensions. This choice is motivated by the evolving attention regarding potential influences on human resources policies and practices from organizational and internal factors to environmental ones based on an institutional approach (Paauwe \& Boselie, 2003).

Employee social media policies can be considered as part of human resources management policies. Their adoption can also be examined from two perspectives: formalization, defined as "the degree to which decisions and working relationships are governed by formal rules, standard policies, and procedures" (Rapert \& Wren, 1998, p. 288); and risk aversion or avoidance defined as the tendency to avoid risks in uncertain situations, and considered as a preventive risk management technique (Adler, Leonard, \& Nordgren, 1999). In this regard, information technology experts consider the adoption of employee social media policies or guidelines as a risk mitigation technique (ISACA, 2010).

\section{Organizational Size}

According to Mintzberg's (1981) theory on organization design, the larger an organization, the more formalized its procedures and rules. A significant body of research supports this positive relationship between organizational size and formalization (Zeffane, 1989). In other 
words, the greater the number of employees, the lesser the ability of managers to directly supervise each individual and the greater the reliance on formalization through written policies, procedures and rules (Chandler, 1990; Freeman, 1999). Also, in small organizations, communication is mostly direct and verbal, whereas in bigger organizations this direct communication channel is difficult to use mainly due to the large number of employees, hence the need to resort to policies that establish procedures to communicate formal company directives and rules (Von Solms \& Von Solms, 2004).

The same idea discussed above arguably applies to social media use by employees. While it might be possible in small organizations to informally communicate to employees the organization's recommendations on online conduct, a similar procedure would be challenging in bigger organizations with larger numbers of employees. Additionally, "institutional theory suggests that larger organizations should adopt more sophisticated and socially responsive (human resources management) activities because these more visible organizations are under more pressure to gain legitimacy" (Jackson \& Schuler, 1995, p. 246). In this regard, employee social media policies can be thought of as sophisticated human resources management related practices showcasing an organization's awareness of the technological challenges presented by these new media and its sensitivity to its corporate online image and the behaviors of its employees. Therefore, the first hypothesis of this study states that the bigger an organization, the more likely it will have an employee social media policy.

Hypothesis 1- Larger organizations are more likely to have employee social media policies.

\section{Industry}


Despite its importance, industry had received scarce attention in research on information systems and technologies (Chiasson \& Davidson, 2005). Commonly studied industries included financial services, retailing, and manufacturing because they were among the first industries to adopt information technologies, thus providing an optimal setting for research (Chiasson \& Davidson, 2005). With the diffusion of information technologies to other industries, new opportunities have opened up for research (Chiasson \& Davidson, 2005) and it has become possible to extend scholarship to a wider variety of industries. Industry was not widely researched in the human resources management literature despite its potential far-reaching implications in the field (Jackson \& Schuler, 1995).

In this study, a high-level categorization of industries is employed, distinguishing between the manufacturing and service sectors. This distinction is usually made in the literature because manufacturing industries and service companies differ in several dynamics (Audretsch, Klomp, \& Thurik, 1997) including innovation patterns (Sheehan, 2006). Furthermore, compared with the manufacturing industries, service firms are more labor-intensive because they rely more on human capital and less on physical infrastructure and machines (Amin, 2010). Given these specificities, human resources management may be more important in the service sector compared with manufacturing industries (Bartel, 2004). It can also be argued that because companies in the service sector are more knowledge-intensive, they may have more knowledge workers using new information technologies in their daily jobs. Consequently, companies in the service sector will be more likely to be exposed to social media use by employees, and will therefore be more sensitive to either possible issues that might arise from such use or potential opportunities that can be harnessed from guiding employee practices. Such awareness might 
result in larger adoption of employee social media policies. Consequently, the second hypothesis is presented as follows:

Hypothesis 2- Compared to manufacturing firms, service sector organizations are more likely to have employee social media policies.

\section{National Culture}

National culture can influence organizational practices and outcomes. A number of existing theoretical frameworks attribute differences in human resources management practices to different internal and external factors without explicitly discussing the role of the sociocultural context (Aycan, 2005). According to the cultural perspective, however, national culture can influence a number of organizational practices (Aycan, 2005). National culture can have influences at the macro level and also affect individual and corporate decision making at the micro-level (Mihet, 2013) and shape human resources policies (Tayeb, 1995). An extensive body of research examined the association between national culture and various organizational outcomes such as job performance, citizenship behavior, and organizational commitment (for a review, see Taras, Kirkman, \& Steel, 2010). Since it is difficult to separate human resources management from national contexts (Tenhiala et al., 2014), and because national culture may play a stronger role in the face of corporate culture, organizations need to take into account national culture differences in the development of human resource policies (Schneider, 1988). The consideration of the external influence of national culture in this study also derives its theoretical relevance from the institutional theory according to which organizations are embedded in a variety of social-institutional influences (Chiasson \& Davidson, 2005; Dimaggio \& Powell, 1983; Senge, 2013). 
Hofstede's (1983) conceptualization of national culture dimensions, which is one of the widely used frameworks to examine cross-cultural differences, is used in this study. Hoftsede's work on culture has been subjected to several criticisms such as doubts about the representativeness of the IBM population on which he based his research (McSweeney, 2002), and the potential obsolescence of the data he used and insufficiency of four or five dimensions to define culture (Baskerville-Morley, 2005). However, Hofstede (2002) responded to criticism indicating that several replications supported the validity of his research. Indeed, reviews of research that incorporated Hofstede's work found that such research supported rather than contradicted Hofstede's conclusions (Kirkman, Lowe, \& Gibson, 2006). Therefore, the cultural dimensions of Hofstede were retained for this study.

The four dimensions of power distance, individualism, masculinity and uncertainty avoidance are posited to be related to the adoption of employee social media policies. First, power distance refers to "the extent to which the less powerful members of organizations and institutions (like the family) accept and expect that power is distributed unequally" (Hofstede, 2011 , p. 9). In large power distance countries, subordinates are expected to be told what to do (Hofstede, 2011), whereas in low distance countries work designs provide more freedom and discretion (Stahl \& Björkman, 2006). Extensive research has found evidence of the link between power distance and a number of work-related outcomes, such as human resources management practices, leadership, and innovation (Daniels \& Greguras, 2014; Keltner, Gruenfeld, \& Anderson, 2003). Evidence also indicates that in societies that feature a high level of power distance, organizations will tend to take fewer risks (Mihet, 2013). Therefore, in high power distance countries, organizations will be more likely to establish social media policies as both a means to tell employees how to behave on social media and as a risk mitigation tool. 
Second, individualism "describes the degree to which individuals are integrated into groups" (Hofstede \& Bond, 1988, p. 10) and refers to the strength of ties people have with their families, tribes, or villages within a society (Hofstede, 1983). A high score on the individualism index means that the members of the culture in question have loose ties, while a low score indicates a collectivist society where members maintain close ties. Individualistic cultures have a higher preference for risk compared to collectivist cultures (Kim \& Park, 2010; Li, Grif, Yue, \& Zhao, 2013; Mihet, 2013) and offer a large amount of freedom to individuals (Hofstede, 1983). Therefore, it is expected that organizations in individualistic cultures will be less likely to adopt employee social media policies thus offering individuals the freedom of assessing their own behaviors on social media, whereas organizations in collectivist cultures will be more likely to adopt these policies as a form of risk avoidance.

Third, masculinity is a cultural dimension that is germane to the extent to which roles are divided between genders in a society (Hofstede, 1983) and the degree to which masculine values such as assertiveness are dominant (Hofstede, 1980). Masculine societies place great value on performance and achievement (Hofstede, 1983). In this type of goal-oriented society, organizations will arguably place higher importance on employee performance and will therefore be more likely to keep a tight grip on social media use in the workplace, on the grounds that it can be a distraction from productivity. This control can be manifested through employee social media policies. Additionally, high levels of masculinity are associated with formalization (Sivakumar \& Nakata, 1996). Therefore, organizations in masculine societies are expected to be more likely to have employee social media policies.

Finally, uncertainty avoidance is related to the way societies deal with uncertain situations (Hofstede, 1983). In countries with high uncertainty avoidance, organizations tend to have 
greater formalization manifested in more written rules and policies (Alkhafaji, 1994; Hofstede, 1980; Schneider \& Barsoux, 2003). In terms of human resources policies, organizations in high uncertainty avoidance cultures favor clear job descriptions and specific rules and policies (Stahl \& Björkman, 2006). Furthermore, organizations in countries with high uncertainty avoidance take fewer risks (Li et al., 2013; Mihet, 2013), and conversely, societies with weak uncertainty avoidance take risks more easily (Hofstede, 1983). In the context of this study, the adoption of employee social media policies can be an organization's way of avoiding ambiguities and risks linked to the use of social technologies. Therefore, organizations in countries that score high on uncertainty avoidance are expected to be more likely to adopt employee social media policies.

In summary, the research hypotheses related to national culture dimensions are as follows:

Hypothesis 3- Organizations from countries with high scores on power distance are more likely to have employee social media policies.

Hypothesis 4- Organizations from countries with high scores on individualism are less likely to have employee social media policies.

Hypothesis 5- Organizations from countries with high scores on masculinity are more likely to have employee social media policies.

Hypothesis 6- Organizations from countries with high scores on uncertainty avoidance are more likely to have employee social media policies.

\section{Methods}

Data collection for this study was conducted as part of a large research project on organizational social media practices in recruitment. An online survey was distributed through the network of an international human resources agency between March and June 2014. This 
multinational agency disseminated the survey to its subsidiaries in different countries around the world, which subsequently distributed it on various social media channels and through mailing lists. The full survey for human resources managers and recruiters contained several sections, and as response was voluntary, survey responses missing answers in the sections relevant for this study were removed. A total of 558 complete answers were retained for this study.

Online surveys were chosen for their multiple advantages, namely fast data collection, cost-effectiveness, convenience, and simplicity (Sue \& Ritter, 2007; Wright, 2005). However, this data collection method also has shortcomings because it was based on convenience sampling, which introduced a risk of self-selection bias which can inhibit the possibility of making generalizations from this study's findings (Wright, 2005). Therefore, the results of this study should be considered in light of these methodological limitations and seen as a first empirical effort on the topic thus requiring further research to support their validity.

Respondents were asked about their organization's size, based on the number of employees (micro $<10$ people, small $<50$, medium $<250$, and large $\geq 250$ ), and whether their organizations had a social media policy or a set of guidelines for employees (yes/no). Respondents were also asked to choose one of twenty business areas, such as "automobiles and parts, "food and beverage", "health care", "media", and "real estate". After data collection, business areas were categorized as manufacturing or services. As respondents provided their organization's country, the scores of the four national culture dimensions of power distance, individualism, masculinity, and uncertainty avoidance were used as retrieved from the data dimension matrix published on Hofstede's official website (Hofstede \& Hofstede, 2015). All scores were within a 100-point range. 


\section{Results}

\section{Sample Characteristics}

The characteristics of the 558 responding organizations are shown in Table 1 . In terms of size, $55.9 \%$ of organizations had 250 employees or more, whereas the rest $(44.1 \%)$ were medium, small or micro companies with fewer than 250 employees. More than half of the responding organizations were members of the services sector $(61.5 \%)$, whereas $38.5 \%$ were from manufacturing industries. The responding organizations were from 27 countries, including Italy (22.8\%), Switzerland (20.1\%), the Netherlands (16.5\%), and Russia (6.1\%). Regarding employee social media policies, $54.7 \%$ of the responding organizations reported having one. These numbers are in line with reported adoption rates that varied between $20 \%$ and $63 \%$ in recent years (Deloitte, 2009; ERC, 2012; Fry, 2013; Macnamara, 2011; Manpower, 2010; Neill \& Moody, 2015; Proskauer, 2011; Protiviti, 2013, 2014; Tufts et al., 2015).

Table 1. Sample's Characteristics

\begin{tabular}{llll}
\hline & & $\mathrm{N}$ & $\%$ \\
\hline Size & Micro: < 10 people & 43 & 7.7 \\
& Small: $<50$ & 99 & 17.7 \\
& Medium: $<250$ & 104 & 18.6 \\
& Large $\geq 250$ & 312 & 55.9 \\
Industry & Manufacturing & 215 & 38.5 \\
& Services & 343 & 61.5 \\
Adoption of employee & & & \\
social media policies & No & & \\
& Yes & 253 & 45.3 \\
& & 305 & 54.7 \\
Country & Italy & 127 & 22.8 \\
& Switzerland & 112 & 20.1 \\
& Netherlands & 92 & 16.5 \\
& Russian Federation & 34 & 6.1 \\
& Greece & 33 & 5.9 \\
& Poland & 26 & 4.7 \\
& Slovenia & 25 & 4.5 \\
\hline
\end{tabular}




\begin{tabular}{lll}
\hline Hungary & 20 & 3.6 \\
Slovakia & 16 & 2.9 \\
Turkey & 13 & 2.3 \\
Bulgaria & 12 & 2.2 \\
USA & 9 & 1.6 \\
Croatia & 8 & 1.4 \\
Czech Republic & 6 & 1.1 \\
Others (Australia, Austria, & \\
Bangladesh, Belgium, & \\
China, Denmark, France, & \\
& Germany, India, Morocco, & \\
Norway, Singapore, & \\
Spain) & \\
\hline
\end{tabular}

The adoption of employee social media policies varied by sector and by organizational size (Table 2). Among the responding manufacturing firms only $35.3 \%$ had a social media policy, and among the responding services firms $66.8 \%$ had one. The adoption rate of employee social media policies was high among large companies of 250 employees or more $(71.2 \%)$ whereas small and medium companies had an adoption rate of around $36 \%$.

Table 2. Adoption of employee social media policies by sector and organization size

\begin{tabular}{|c|c|c|c|c|c|c|c|}
\hline & & \multicolumn{2}{|c|}{ Do not have policie } & \multicolumn{2}{|c|}{ Have policies } & \multicolumn{2}{|c|}{ Total } \\
\hline & & $\mathrm{N}$ & $\%$ & $\mathrm{~N}$ & $\%$ & $\mathrm{~N}$ & $\%$ \\
\hline \multirow[t]{2}{*}{ Sector } & Manufacturing & 139 & 64.7 & 76 & 35.3 & 215 & 100 \\
\hline & Services & 114 & 33.2 & 229 & 66.8 & 343 & 100 \\
\hline \multirow[t]{4}{*}{ Size } & Micro: $<10$ people & 34 & 79.1 & 9 & 20.9 & 43 & 100 \\
\hline & Small: $<50$ & 63 & 63.6 & 36 & 36.4 & 99 & 100 \\
\hline & Medium: $<250$ & 66 & 63.5 & 38 & 36.5 & 104 & 100 \\
\hline & Large: $\geq 250$ & 90 & 28.8 & 222 & 71.2 & 312 & 100 \\
\hline
\end{tabular}

\section{Data Analysis}

Logistic regression was conducted to investigate the relationship between the independent variables and the adoption of employee social media policies. This technique is used to model 
the relationship between a categorical dependent variable and one or several explanatory variables (Hosmer \& Lemeshow, 2004). In many fields, the logistic regression model has become the standard method of analysis when the outcome variable is discrete (Hosmer \& Lemeshow, 2004). To run this analysis, two assumptions were verified. First, collinearity diagnostics were conducted and neither tolerance nor VIF measures displayed worrisome scores for any of the independent variables. Second, the number of events per variable in the examined sample was acceptable thus eliminating risks of bias (Peduzzi, Concato, Kemper, Holford, \& Feinstein, 1996).

Logistic regression analysis was conducted to predict the adoption of employee social media policies based on the organization's size and industry and the national culture dimensions of power distance, individualism, masculinity, and uncertainty avoidance. The dependent variable was the adoption of social media policies, coded as 1 if the organization had such a document, and 0 if it did not. The full model containing all predictors was statistically significant $(\chi 2(8, \mathrm{~N}=558)=189.64, \mathrm{p}<.001)$ indicating that it was able to distinguish between organizations that adopted employee social media policies and those that did not. The model as a whole explained between $28.8 \%\left(\right.$ Cox and Snell $R^{2}$ ) and $38.5 \%\left(\right.$ Nagelkerke $R^{2}$ ) of the variance in the organizational adoption of social media policies. The model's prediction success overall was $73.1 \%$ (73.1\% for non-adoption and $73.1 \%$ for adoption), which constituted an improvement compared to the constant only model (54.7 prediction success). The Wald criterion (Table 3 ) showed that size, industry, power distance, individualism, masculinity, and uncertainty avoidance all made a significant contribution to the model.

Finally, the statistical model was checked for goodness of fit because failure to assess it on this ground may lead to incorrect or misleading conclusions (Hosmer, Taber, \& Lemeshow, 
1991). The Hosmer and Lemeshow goodness-of-fit test indicated that the logistic model's estimate for the data was at an acceptable level (0.061). In summary, the results of the logistic regression analysis provided support for Hypotheses 1, 2, and 6, , but not for Hypotheses 3, 4, and 5 .

Table 3. Variables in the Equation

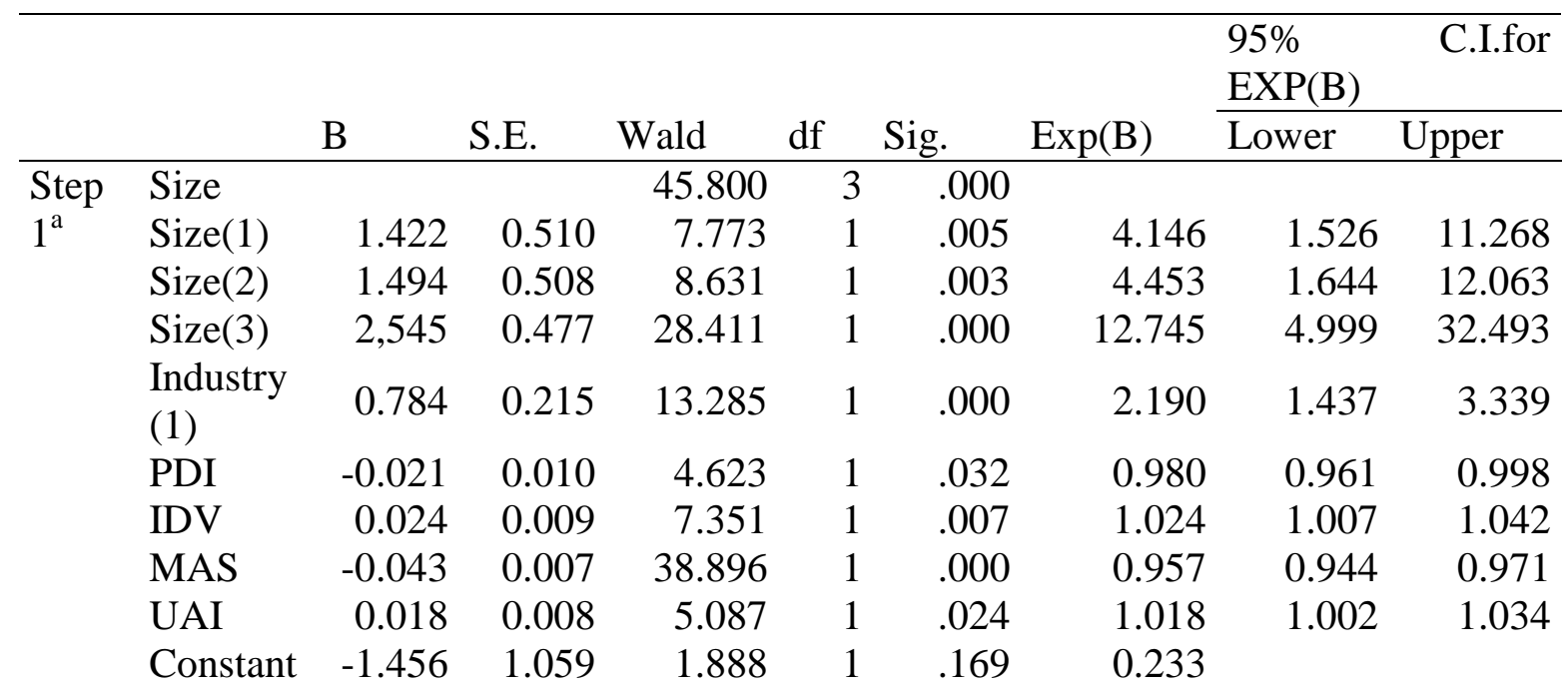

a. Variable(s) entered on step 1: Size, Industry, PDI, IDV, MAS and UAI.

Note: $\mathrm{CI}=$ confidence interval; $\mathrm{PDI}=$ Power Distance Index, IDV = Individualism, MAS $=$ Masculinity; UAI = Uncertainty Avoidance Index.

\section{Discussion}

Based on the theoretical foundations of the institutional approach, this study examined six determinants of social media policy adoption in a sample of 558 organizations. The examined factors were organizational size, industry, and the four national culture dimensions of power distance, individualism, masculinity, and uncertainty avoidance. The results of a logistic regression analysis showed that all six predictors were associated with the adoption of employee social media policies but not necessarily in the hypothesized directions. 
The first hypothesis was supported with results showing that larger organizations were more likely to adopt employee social media policies. This finding goes in line with one of the ideas of organization design theory, which states that the larger an organization, the more employees to manage, and the more need for rules and policies to organize workplace behaviors.

The second hypothesis was also supported as service sector organizations were found to be more likely to have social media policies. This finding was expected due to the labor-intensive nature of the services sector and its heavy reliance on human capital, which entail the need for more human resource management efforts and accompanying workplace policies.

The third hypothesis was not supported because organizations from more power-distant countries were not found to be the most likely to have an employee social media policy but rather the least likely to do so. It is possible that in countries where people accept authority they also automatically recognize their boundaries and prefer to not take risks with social media use. In these power distant countries individuals might be readily prone to respond to the authority of those in power and thus act accordingly without necessarily requiring the adoption of policies.

The fourth hypothesis was also not supported because organizations from more individualistic countries were not found to be the least likely to have an employee social media policy but rather the most likely to do so, It is possible that because people in individualistic cultures tend to seek their own interests, organizations would be more sensitive to social mediarelated risks that might result from employees prioritizing their interests over those of their employers. As a consequence, organizations in individualistic cultures might prefer to establish rules for the online conduct for their employees.

The fifth hypothesis was not supported either because organizations from more masculine countries were not found to be the most likely to have an employee social media policy but 
rather the least likely to do so, This finding could be explained by the fact that feminine countries, scoring low on the masculinity index, strive more for harmony in society, which can be achieved through rules and guidelines.

As for the sixth hypothesis, as expected, the odds of adopting employee social media policies were larger for organizations located in countries that scored higher on uncertainty avoidance, which is arguably motivated by the general tendency of such societies to resort to rules and policies to confront situations marked by uncertainty. The use of social media in work contexts is indeed marked with uncertainty due to the proliferation of communication channels and the large audiences involved in exchanges (Bucher et al., 2013).

The findings of this study provide support to the widespread idea among practitioners stating that social media policies should not be considered as a one size fits all but rather as an effort to be tailored to each organization, depending on its size and industry, as well as the cultural characteristics of the country where it is based. These findings are of particular importance to organizational policy makers because an organization's policy can lose its effectiveness across different cultural environments (Hofstede, 1980). Organizational policies might work differently in different cultural contexts, and this is particularly relevant for multinational organizations for which subsidiaries and the mother company are established in different cultures (Hofstede, 1980).

\section{Limitations and Future Research}

The limitations of this study present numerous opportunities for future research. First, although social media policies adoption rates in the surveyed sample of organizations matched reported rates in practice, the survey dissemination approach may have presented a threat to the 
representativeness of the sample. Future research is thus required to employ more robust sampling techniques.

Second, the scope of examining employee social media policies was limited to adoption without distinguishing between the types and contents of these policies. Future research may take into account differences between restrictive policies that entail retributions and simple guidelines that provide recommendations. This distinction is important because the two types of policies might appeal to different organizational and cultural settings and may have different outcomes in terms of organizational attractiveness and employee retention.

Third, the investigation of the impact of national culture on a human resources management practice, without including the mediating role of internal work culture, might represent a shortcoming. A mediated model is theoretically superior to the nonmediated model (Aycan, Kanungo, \& Sinha, 1999) and should thus be favored in future research.

Finally, measuring cultural differences using secondary data might represent a limitation, as it overlooks within-country variance (Taras et al., 2010). It may be more suitable to assess cultural values using primary data in future studies to ensure greater predictive power compared to secondary sources-based cultural dimensions (Taras et al., 2010).

The growing scholarship on employee social media policies offers many other avenues for future investigation. There is need to examine the implementation and outcomes of social media policies (Jacobson \& Tufts, 2013) and to conduct a cross-cultural investigation of how Millennials perceive different social media policies (Cho et al., 2013).

Further research is also needed to study other organizational factors that can predict the adoption of employee social media policies and their level of openness or restrictiveness. Further examination of more external factors that might influence the adoption of social media policies 
can continue to use the institutional theory (Dimaggio \& Powell, 1983). In this context, two factors can be of particular interest, namely the legal environment of organizations manifested in the strictness of employment laws, and the possibility that the adoption of employee social media policies is a mimetic behavior driven by the novelty of social media-related issues (Mergel \& Bretschneider, 2013). Given the focus of existing legal scholarship related to employee social media policies on the American context (A. El Ouirdi, El Ouirdi, Segers, \& Henderickx, 2015), future research may also investigate regulations in other geographical areas. 


\section{References}

Adler, T. R., Leonard, J. G., \& Nordgren, R. K. (1999). Improving risk management: moving from risk elimination to risk avoidance. Information and Software Technology, 41(1), 2934.

Alkhafaji, A. (1994). Competitive Global Management-Principles and Strategies. Delray Beach: St Lucie Press.

Amin, M. (2010). How Do Manufacturing and Service Firms Differ within the Informal Sector? Enterprise Note Series.

Audretsch, D. B., Klomp, L., \& Thurik, A. R. (1997). Do Services Differ from Manufacturing? The Post-Entry Performance of Firms in Dutch Services. Tinbergen Institute Discussion Paper.

Aycan, Z. (2005). The interplay between cultural and institutional/structural contingencies in human resource management practices. The International Journal of Human Resource Management, 16(7), 1083-1119.

Aycan, Z., Kanungo, R. N., \& Sinha, J. B. P. (1999). Organizational Culture and Human Resource Management Practices: The Model of Culture Fit. Journal of Cross-Cultural Psychology, 30(4), 501-526.

Bartel, A. P. (2004). Human resource management and organizational performance: Evidence from retail banking. Industrial and Labor Relations Review, 57(2), 181-203.

Barzilai-Nahon, K., \& Mason, R. M. (2010). How Executives Perceive the Net Generation. Information, Communication \& Society, 13(3), 396-418.

Baskerville-Morley, R. F. (2005). A research note: The unfinished business of culture. Accounting, Organizations and Society, 30(4), 389-391.

Berkowitz, A. D., Downes, J. I., \& Burdick, J. L. (2012). National Labor Relations Act Update. Employee Relations Law Journal, 37(4), 39-66.

Brice, R., Fifer, S., \& Naron, G. (2012). Social Media in the Workplace: The NLRB Speaks. Intellectual Property \& Technology Law Journal, 24(10), 13-17.

Bucher, E., Fieseler, C., \& Suphan, A. (2013). The Stress Potential of Social Media in the Workplace. Information, Communication \& Society, 16(10), 1639-1667.

Cain, J. (2011). Social media in health care: the case for organizational policy and employee education. American Journal of Health-System Pharmacy, 68(11), 1036-40.

Cavico, F. J., Mujtaba, B. G., Muffler, S. C., \& Samuel, M. (2013). Social Media and the Workplace: Legal, Ethical, and Practical Considerations for Management. Journal of Law, Policy and Globalization, 12, 1-47.

Chandler, A. D. (1990). Strategy and structure: Chapters in the history of the industrial enterprise. Cambridge: MIT press.

Charoensukmongkol, P. (2014). Effects of support and job demands on social media use and 
work outcomes. Computers in Human Behavior, 36, 340-349.

Chiasson, M. W., \& Davidson, E. (2005). Taking industry seriously in information systems research. MIS Quarterly, 29(4), 591-605.

Cho, J., Park, D. J., \& Ordonez, Z. (2013). Communication-oriented person-organization fit as a key factor of job-seeking behaviors: millennials' social media use and attitudes toward organizational social media policies. Cyberpsychology, Behavior and Social Networking, 16(11), 794-799.

Chretien, K. C., Greysen, S. R., Chretien, J.-P., \& Kind, T. (2009). Online posting of unprofessional content by medical students. JAMA: Journal of the American Medical Association, 302(12), 1309-1315.

Cisco. (2011). 2011 Cisco Connected World Technology Report.

Daniels, M. A., \& Greguras, G. J. (2014). Exploring the Nature of Power Distance: Implications for Micro- and Macro-Level Theories, Processes, and Outcomes. Journal of Management, $40(5), 1202-1229$.

Davison, H. K., Maraist, C., \& Bing, M. N. (2011). Friend or Foe? The Promise and Pitfalls of Using Social Networking Sites for HR Decisions. Journal of Business and Psychology, 26(2), 153-159.

Decamp, M. (2013). Physicians, social media, and conflict of interest. Journal of General Internal Medicine, 28, 299-303.

Deloitte. (2009). Social Networking and Reputational Risk in the Workplace.

Dimaggio, P. J., \& Powell, W. W. (1983). The Iron Cage Revisited: Institutional Isomorphism and Collective Rationality in Organizational Fields. American Sociological Review, 48(2), $147-160$.

Dreher, S. (2014). Social media and the world of work: A strategic approach to employees' participation in social media. Corporate Communications: An International Journal, 19(4), 344-356.

El Ouirdi, A., El Ouirdi, M., Segers, J., \& Henderickx, E. (2014). Social Media Guidelines and Policies: an Exploratory Study. In A. Rospigliosi \& S. Greener (Eds.), Proceedings of the European Conference on Social Media (pp. 737-739). University of Brighton.

El Ouirdi, A., El Ouirdi, M., Segers, J., \& Henderickx, E. (2015). Employees' use of social media technologies: a methodological and thematic review. Behaviour \& Information Technology, 34(5), 454-464.

El Ouirdi, M., El Ouirdi, A., Segers, J., \& Henderickx, E. (2014). Social Media Conceptualization and Taxonomy: A Lasswellian Framework. Journal of Creative Communications, 9(2), 107-126.

Elefant, C. (2011). The "Power" of Social Media: Legal Issues \& Best Practices For Utilities Engaging Social Media. Energy Law Journal, 32(1), 1-56.

ERC. (2012). 2012 ERC Social Media in the Workplace Survey. Mayfield Village. 
Eysenbach, G. (2008). Medicine 2.0: Social networking, collaboration, participation, apomediation, and openness. Journal of Medical Internet Research, 10(3).

Fast, I., Sørensen, K., Brand, H., \& Suggs, L. S. (2015). Social Media for Public Health: An Exploratory Policy Analysis. European Journal of Public Health, 25(1), 162-166.

Freeman, R. M. (1999). Correctional organization and management: Public policy challenges, behavior, and structure. Boston: Elsevier.

Fry, W. (2013). William Fry Employment Report 2013 - Social Media in the Workplace. Dublin.

Geyer, S., \& Krumay, B. (2015). Development of a Social Media Maturity Model - A Grounded Theory Approach. In 2015 48th Hawaii International Conference on System Sciences (pp. 1859-1868).

Greysen, S. R., Kind, T., \& Chretien, K. C. (2010). Online professionalism and the mirror of social media. Journal of General Internal Medicine, 25(11), 1227-1229.

Hidy, K. M., \& Mcdonald, M. S. E. (2013). Risky Business: The Legal Implications of Social Media's Increasing Role in Employment Decisions. Journal of Legal Studies in Business, 18, 69-107.

Hofstede, G. (1980). Motivation, leadership, and organization: Do American theories apply abroad? Organizational Dynamics, 9(1), 42-63.

Hofstede, G. (1983). The cultural relativity of organizational practices and theories. Journal of International Business Studies, 14(2), 75-89.

Hofstede, G. (2002). Dimensions Do Not Exist: A Reply to Brendan McSweeney. Human Relations, 55(11), 1355-1361.

Hofstede, G. (2011). Dimensionalizing cultures: The Hofstede model in context. Online Readings in Psychology and Culture, 2(1), 1-26.

Hofstede, G., \& Bond, M. H. (1988). The Confucius connection: From cultural roots to economic growth. Organizational Dynamics, 16(4), 5-21.

Hofstede, G., \& Hofstede, G. H. (2015). Research and VSM. Retrieved June 27, 2015, from http://geerthofstede.nl/research--vsm

Hosmer, D. W., \& Lemeshow, S. (2004). Applied Logistic Regression (Second). New York: John Wiley \& Sons, Inc.

Hosmer, D. W., Taber, S., \& Lemeshow, S. (1991). The importance of assessing the fit of logistic regression models: a case study. American Journal of Public Health, 81(12), 16301635 .

Hrdinová, J., Helbig, N., \& Peters, C. S. (2010). Designing Social Media Policy for Government: Eight Essential Elements. Albany.

Hudson, S. C., \& Roberts, K. K. (2011). Drafting and Implementing an Effective Social Media Policy. Texas Wesleyan Law Review, 18, 767-796.

Husin, M., \& Hanisch, J. (2011a). Social Media and Organisation Policy (SoMeOP): Finding the Perfect Balance. In European Conference on Information Systems (ECIS) (p. Paper 253). 
Husin, M., \& Hanisch, J. (2011b). Utilising the Social Media and Organization Policy (SOMEOP) Framework: An Example of Organizational Policy Development Within a Public Sector Entity. In European Conference on Information Systems (ECIS).

ISACA. (2010). Social Media: Business Benefits and Security, Governance and Assurance Perspectives. Rolling Meadows.

Jackson, S. E., \& Schuler, R. S. (1995). Understanding human resource management in the context of organizations and their environments. Annual Review of Psychology, 46, 237264.

Jacobson, W. S., \& Tufts, S. H. (2013). To Post or Not to Post: Employee Rights and Social Media. Review of Public Personnel Administration, 33(1), 84-107.

Johnston, J. (2015). "Loose tweets sink fleets" and other sage advice: social media governance, policies and guidelines. Journal of Public Affairs, 15(22), 175-187.

Kaganer, E., \& Vaast, E. (2010). Responding to the (almost) unknown : Social representations and corporate policies of social media. In ICIS 2010 Proceedings (pp. 1-19).

Kaupins, G., \& Park, S. (2011). Legal and Ethical Implications of Corporate Social Networks. Employee Responsibilities and Rights Journal, 23(2), 83-99.

Keltner, D., Gruenfeld, D. H., \& Anderson, C. (2003). Power, Approach, and Inhibition. Psychological Review, 110(2), 265.

Kennedy, R. (2013). Sharing is Airing: Employee Concerted Activity on Social Media after Hispanic United. Duke Law \& Technology Review, 12(1), 182-199.

Kietzmann, J. H., Hermkens, K., McCarthy, I. P., \& Silvestre, B. S. (2011). Social media? Get serious! Understanding the functional building blocks of social media. Business Horizons, 54(3), 241-251.

Kim, D.-Y., \& Park, J. (2010). Cultural differences in risk: The group facilitation effect. Judgment and Decision Making, 5(5), 380-390.

Kind, T., Genrich, G., Sodhi, A., \& Chretien, K. C. (2010). Social media policies at US medical schools. Medical Education Online, 15, 2-8.

Kirby, S. J., \& Raphan, E. (2014). The NLRB's Continued Regulation of Social Media in the Workplace. Journal of Internet Law, 18(2), 1,13-17.

Kirkman, B. L., Lowe, K. B., \& Gibson, C. B. (2006). A Quarter Century of “Culture's Consequences": A Review of Empirical Research Incorporating Hofstede's Cultural Values Framework. Journal of International Business Studies, 37(3), 285-320.

Krüger, N., Brockmann, T., \& Stieglitz, S. (2013). A Framework for Enterprise Social Media Guidelines. In Proceedings of the Nineteenth Americas Conference on Information Systems.

Laick, S., \& Dean, A. A. (2011). Using Web 2.0 Technology in Personnel Marketing to Transmit Corporate Culture. International Journal of Management Cases.

Li, K., Grif, D., Yue, H., \& Zhao, L. (2013). How does culture influence corporate risk-taking? Journal of Corporate Finance, 23, 1-22. 
Linke, A., \& Zerfass, A. (2013). Social media governance: regulatory frameworks for successful online communications. Journal of Communication Management, 17(3), 270-286.

Macnamara, J. (2011). Social Media Strategy \& Governance: Gaps, risk and opportunities. Sydney.

Manpower. (2010). Social Networks vs. Management? Harness the Power of Social Media. Milwaukee.

McSweeney, B. (2002). Hofstede's Model of National Cultural Differences and their Consequences: A Triumph of Faith - a Failure of Analysis. Human Relations, 55(1), 89118.

Mergel, I., \& Bretschneider, S. I. (2013). A Three-Stage Adoption Process for Social Media Use in Government. Public Administration Review, 73(3), 390-400.

Mihet, R. (2013). Effects of culture on firm risk-taking: A cross-country and cross-industry analysis. Journal of Cultural Economics, 37(1), 109-151.

Mintzberg, H. (1981). Organization design: fashion of fit? Harvard Business Review, (JanuaryFebruary), 103-116.

Murphy, S. A. (2007). Leading a Multigenerational Workforce. Washington D.C.

Murthy, D., Hastings, C. M., \& Mawrie, S. A. (2014). The Use of Social Media to Foster Trust, Mentorship, and Collaboration in Scientific Organizations. Bulletin of Science, Technology \& Society, 34(5-6), 170-182.

National Labor Relations Board. (2012). Memorandum OM 12-59.

Neal, L. K. (2012). The Virtual Water Cooler and the NLRB: Concerted Activity in the Age of Facebook. Washington and Lee Law Review, 69(3), 1715-1758.

Neill, M. S., \& Moody, M. (2015). Who is responsible for what? Examining strategic roles in social media management. Public Relations Review, 41(1), 109-118.

O'Brien, C. N. (2014). The Top Ten NLRB Cases on Facebook Firings and Employer Social Media Policies. Oregon Law Review, 92(2), 337-380.

Oakley, M., \& Spallek, H. (2012). Social media in dental education: a call for research and action. Journal of Dental Education, 76(3), 279-87.

Paauwe, J., \& Boselie, P. (2003). Challenging "strategic HRM" and the relevance of the institutional setting. Human Resource Management Journal, 13(3), 56-70.

Peduzzi, P., Concato, J., Kemper, E., Holford, T. R., \& Feinstein, A. R. (1996). A simulation study of the number of events per variable in logistic regression analysis. Journal of Clinical Epidemiology, 49(12), 1373-1379.

Proskauer. (2011). Survey: Social Networks in the Workplace Around the World. London.

Protiviti. (2013). 2013 Internal Audit Capabilities and Needs Survey Report: Assessing the Top Priorities for Internal Audit Functions.

Protiviti. (2014). Assessing the Top Priorities for Internal Audit Functions: 2014 Internal Audit 
Capabilities and Needs Survey.

Rapert, M. I., \& Wren, B. M. (1998). Reconsidering organizational structure: A dual perspective on frameworks and processes. Journal of Managerial Issues, 10(3), 287-302.

Sagie, A., \& Aycan, Z. (2003). A Cross-Cultural Analysis of Participative Decision-Making in Organizations. Human Relations, 56(4), 453-473.

Schneider, S. C. (1988). Natinal Vs. Corporate Culture: Implications for Human Resources Management. Human Resource Management, 27(2), 231-246.

Schneider, S. C., \& Barsoux, J.-L. (2003). Managing across cultures. Harlow: Pearson Education.

Senge, K. (2013). The "New Institutionalism" in Organization Theory: Bringing Society and Culture Back In. The American Sociologist, 44(1), 76-95.

Sheehan, J. (2006). Understanding Service Sector Innovation. Communications of the ACM, 49(7), 42-47.

Sivakumar, K., \& Nakata, C. (1996). National Culture and New Product Development: An Integrative Review. The Journal of Marketing, 60(1), 61-72.

Stahl, G. K., \& Björkman, I. (Eds.). (2006). Handbook of Research in International Human Resource Management. Cheltenham: Edward Elgar Publishing Limited.

Sue, V. M., \& Ritter, L. A. (2007). Conducting Online Surveys. Uma ética para quantos? (Vol. XXXIII). Lost Angelos: SAGE Publications.

Taras, V., Kirkman, B. L., \& Steel, P. (2010). Examining the impact of Culture's consequences: A three-decade, multilevel, meta-analytic review of Hofstede's cultural value dimensions. Journal of Applied Psychology, 95(3), 405-439.

Tayeb, M. (1995). The competitive advantage of nations: the role of HRM and its socio-cultural context. The International Journal of Human Resource Management, 6(3), 588-605.

Tenhiala, A., Giluk, T. L., Kepes, S., Simon, C., Oh, I.-S., \& Kim, S. (2014). The ResearchPractice Gap in Human Resource Management: A Cross-Cultural Study. Human Resource Management.

Thornthwaite, L. (2013). Chilling Times: Labour Law and the Regulations of Social Media Policies. In Labour Law Research Network Inaugural Conference.

Tufts, S. H., Jacobson, W. S., \& Stevens, M. S. (2015). Status Update: Social Media and Local Government Human Resource Practices. Review of Public Personnel Administration, 35(2), 193-207.

Vaast, E., \& Kaganer, E. (2013). Social media affordances and governance in the workplace: An examination of organizational policies. Journal of Computer-Mediated Communication, 19(1), 78-101.

Von Solms, R., \& Von Solms, B. (2004). From policies to culture. Computers and Security, 23(4), 275-279.

Wright, K. B. (2005). Researching Internet-Based Populations: Advantages and Disadvantages 
of Online Survey Research, Online Questionnaire Authoring Software Packages, and Web Survey Services. Journal of Computer-Mediated Communication, 10(3), 00.

Yan, Y., Davison, R. M., \& Mo, C. (2013). Employee creativity formation: The roles of knowledge seeking, knowledge contributing and flow experience in Web 2.0 virtual communities. Computers in Human Behavior, 29(5), 1923-1932.

Younkins, L. R. (2013). \#IHateMyBoss: Rethinking the NLRB's Approach to Social Media Policies. Brook. J. Corp. Fin. \& Com. L., 8(1), 222-252.

Zeffane, R. M. (1989). Centralization or formalization? Indifference curves for strategies of control. Organization Studies, 10(3), 327-352.

Zerfass, A., Fink, S., \& Linke, A. (2011). Social Media Governance: Regulatory frameworks as drivers of success in online communications. In 14th International Public Relations Research Conference (pp. 1026-1047). 